\title{
SISTEMA FINANCEIRO E CRESCIMENTO ECONÔMICO: UMA APLICAÇÃO DE REGRESSÃO QUANTÍLICA*
}

\author{
Everton Nunes da Silva ${ }^{\S}$ \\ Sabino da Silva Porto Júnior ${ }^{\not}$
}

\begin{abstract}
RESUMO
Este trabalho tem o objetivo de analisar teórica e empiricamente a suposta relação positiva existente entre desenvolvimento financeiro e crescimento econômico. O sistema financeiro influencia o crescimento econômico devido às funções que este desempenha, tais como: a) mobilização de recursos; b) alocação dos recursos no espaço e no tempo; c) administração do risco; d) seleção e monitoração de empresas; e e) produção e divulgação de informação. Para analisar estes aspectos, aplicou-se a técnica de regressão quantílica, a partir de dados de 77 países, o que permitiu um mapeamento mais completo do impacto gerado pelas medidas de desenvolvimento financeiro na distribuição condicional da variável resposta (medidas de crescimento econômico). As estimativas obtidas permitem concluir que: a) há uma relação positiva entre desenvolvimento financeiro e crescimento econômico; e b) quanto maior o quantil (isto é, maior a taxa de crescimento econômico), maior é a contribuição do sistema financeiro para o crescimento econômico.
\end{abstract}

Palavras-chave: crescimento econômico, assimetria de informação, intermediação financeira.

\begin{abstract}
This work has the objective to analyze the relationship between financial development and economic growth. The financial system influences the economic growth due to the functions that it plays, such as: a) the mobilization of resources; b) allocation of resources in the space and in the time; c) administration of risk; d) selection and monitoration of companies; and e) production and spreading of information. It was applied technique of quantile regression to analyze these aspects from data of 77 countries. This econometric method allows a more complete mapping of the impact generated from the measures of financial development throughout the conditional distribution of the response variable (measures of economic growth). The estimates allow concluding that: a) there is a positive relation between financial development and economic growth; and b) bigger the quantile (that is, greater the rate of economic growth), greater is the contribution of the financial system for the economic growth.
\end{abstract}

Key words: economic growth, asymmetric information, financial intermediation.

JEL classification: O4, D8, G2.

\footnotetext{
* Os autores agradecem a Giácomo Balbinotto Neto pelos dados cedidos.

$\S \quad$ Doutorando UFRGS e bolsista CNPq. E-mail: everton@ppgel.ppge.ufrgs.br.

a Professor UFRGS. E-mail: sabino@ppge.ufrgs.br.

Endereço de contato: Universidade Federal do Rio Grande do Sul - Faculdade de Ciências Econômicas - Programa de Pós-Graduação em Economia. Av. João Pessoa, 52 - sala 33B - $3^{\circ}$ andar - Centro - Porto Alegre/RS - CEP 90040-000.

Recebido em outubro de 2004. Aceito em junho de 2006.
} 


\section{INTRODUÇÃO}

Desde meados dos anos 1980 a teoria do crescimento econômico vem sendo revigorada como conseqüência do surgimento de uma vasta variedade de modelos que buscaram sintetizar os determinantes do crescimento, isto é, do aumento da capacidade produtiva de uma economia. Encontrar alternativas para explicar o resíduo de Solow ${ }^{1}$ tornou-se assunto de alta relevância na agenda acadêmica. Como resultado desse interesse, surgiram os modelos de Romer (1986), Rebelo (1991), Lucas (1988) e Mankiw, Romer e Weil (1992), ${ }^{2}$ os quais frisaram que o conhecimento, o progresso técnico e o capital humano são fatores determinantes para o crescimento econômico.

Nesse cenário, ressurge o interesse pelas considerações de Schumpeter (1911) referente ao papel relevante do sistema financeiro para o crescimento econômico, bem como são revistos os trabalhos de Goldsmith (1969) e Shaw (1973), estudiosos que encontraram evidências empíricas acerca da relação positiva entre o mercado financeiro e o crescimento econômico. Dentre os autores que construíram modelos conectando o desenvolvimento financeiro e crescimento econômico encontram-se: Bencivenga e Smith (1991); Khan (1999); Pagano (1993); Becsi e Wang (1997); Levine (1997); Bebczuk (2001). A idéia central desses modelos refere-se ao fato de a intermediação financeira permitir maior eficiência na alocação dos recursos financeiros, o que corresponde a maior captação de poupança e, conseqüentemente, maiores recursos para emprestar, que podem se destinar ao melhoramento do capital físico e humano, o que, por sua vez, gera crescimento econômico.

A proposta deste trabalho é mostrar os argumentos da literatura afim sobre a relevância do sistema financeiro como um dos determinantes do crescimento econômico, além de testar algumas hipóteses sobre a existência ou não de uma correlação positiva entre desenvolvimento financeiro e crescimento para dados disponíveis de 77 países. ${ }^{3}$ Utiliza-se a técnica de Regressão Quantílica porque esta fornece uma visão mais detalhada dos impactos gerados pelo sistema financeiro na distribuição condicional da variável resposta (crescimento econômico). Para alcançar tal objetivo, o trabalho estrutura-se da seguinte forma: a seção 2 descreve o ambiente de informação assimétrica no qual o mercado financeiro está incluso, além de descrever suas eventuais virtudes em relação à eficiência alocativa dos recursos financeiros; a seção 3 mostra as funções do sistema financeiro em uma economia de mercado; a seção 4 expõe a técnica aplicada no teste empírico; a seção 5 descreve os dados e analisa os resultados obtidos; e a seção 6 sumaria algumas conclusões.

\section{SISTEMA FINANCEIRO: FATORES FAVORÁVEIS À EFICIÊNCIA ALOCATIVA}

O sistema financeiro é composto de vários intermediários, em que fazem parte o Banco Central, além de bancos comerciais e de investimentos, corretoras de valores, fundos de investimentos, fundos de pensão, bolsas de valores e companhias de seguro. Contudo, a literatura da área apresenta uma certa tendência a colocar os bancos como sendo os representantes legítimos ${ }^{4}$ do sistema

1 O artigo seminal de Robert Solow intitulado "A contribution to the theory of economic growth", publicado em 1956, teve grande repercussão no meio acadêmico, sendo considerado o modelo mais completo que formaliza uma teoria de crescimento econômico. Sua aceitação era praticamente unânime entre os teóricos. Então, convencionou-se definir tudo que não era explicado pelo modelo de Solow como Resíduo de Solow, ou de forma igualmente conhecida, medida de nossa ignorância.

2 Os três primeiros autores fazem parte do que se denominou "Teoria do Crescimento Endógeno" e os demais fazem uma releitura da teoria neoclássica do crescimento, introduzindo capital humano no modelo de Solow. Para uma referência sobre crescimento econômico, ver Romer (2001) e Barro e Sala-i-Martin (1995).

3 Este trabalho não visa abordar a questão da causalidade entre sistema financeiro e crescimento econômico, visto que, para isso, seria necessária uma análise de séries de tempo em vez de dados cross-section. Ver Levine et al. (2002), entre outros, para uma abordagem sobre causalidade entre sistema financeiro e crescimento econômico.

4 Apesar de os bancos serem os principais representantes do sistema financeiro, a análise pode ser facilmente estendida para os demais componentes do sistema financeiro, sem perda de generalidade. 
financeiro. Uma possível justificativa pode está relacionada ao fato de os bancos serem responsáveis por mais de $60 \%$ da fonte de fundos externos de empresas não-financeiras. ${ }^{5}$

A existência do sistema financeiro está condicionada a imperfeições de mercado, tais como falhas no canal de transmissão de informação entre os agentes econômicos e distanciamento do mercado competitivo (poder de mercado). As trocas entre os agentes tornam-se mais onerosas quanto mais graves são as falhas de mercado, podendo, como caso limite, inviabilizá-las. A intermediação financeira surge, então, como um mecanismo para minimizar tais imperfeições, facilitando (intermediando) a alocação dos recursos entre poupadores e tomadores de empréstimos e, dessa forma, transmitindo aos investimentos produtivos os recursos necessários.

\section{Figura 1 - Esquema simples do funcionamento do sistema financeiro}

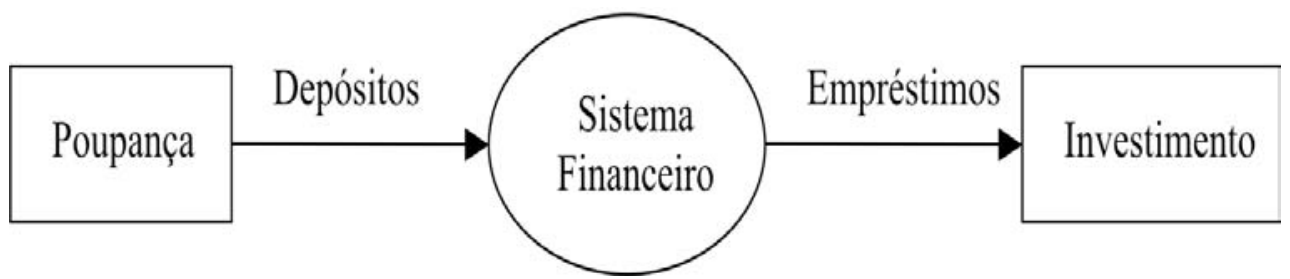

Fonte: Bebczuk, 2003.

Na Figura 1 pode-se visualizar que o ato de poupar é disjunto do ato de investir, isto é, o indivíduo que poupa, em sua grande maioria, não é o mesmo que realiza os investimentos produtivos. Assim, quando a economia se afasta do ambiente competitivo, há perda de recursos para o setor produtivo, pois os custos de transação e os custos de informação envolvidos em uma transação podem somar quantias que inviabilizem as transações. Portanto, a eficiência propiciada pelo sistema financeiro reside exatamente na redução dos custos de transação e custos de informação no momento em que o contrato financeiro é firmado.

Os custos de transação referem-se aos gastos envolvidos na transação financeira, tais como o processo de reuniões entre os interessados, o pagamento advocatício para redação de contrato, entre outros. Os custos de transação podem ser reduzidos, substancialmente, com a introdução dos intermediários financeiros (bancos), pois estes desenvolveram uma especialização (expertise) nessa atividade, obtendo, assim, vantagens relativas a ganhos de escala, isto é, a redução do custo à medida que o número de transações é aumentado. Segundo Mishkin (2000), os baixos custos de transação de um intermediário financeiro significam que ele pode fornecer a seus clientes serviços de liquidez, que permitam agilidade para os clientes ao realizar as transações.

Custos de informação, por sua vez, dizem respeito aos custos provenientes da assimetria de informação entre o agente e o principal, ou seja, uma das partes do contrato está mais informada do que a outra. Quando há assimetria de informação, conflitos de interesses tendem a ocorrer. Há dois tipos de problemas vindos da assimetria de informação: seleção adversa e risco moral. O primeiro ocorre antes que a transação ocorra. Seleção adversa torna-se um problema no mercado financeiro devido ao fato de que é mais provável que tomadores com riscos de crédito elevados demandem crédito, aumentando, assim, a probabilidade que estes sejam selecionados. Sabendo de antemão dessa relação, os emprestadores podem decidir não conceder empréstimos, pois não conseguem distinguir

5 Este dado se refere à economia dos EUA. Ver Mishkin (2000). 
os bons dos maus tomadores de crédito. ${ }^{6} \mathrm{O}$ segundo ocorre depois que a transação é efetuada. $\mathrm{O}$ risco moral se refere ao risco de os tomadores de crédito se engajarem em atividades indesejáveis do ponto de vista do emprestador, pois tais atividades reduzem a probabilidade de que o empréstimo seja pago. Da mesma forma que a seleção adversa, o risco moral pode ocasionar o fim da concessão de crédito como uma forma de proteção ao risco do emprestador.

Como os problemas provocados pela informação assimétrica podem colapsar o mercado de crédito, torna-se fundamental a presença de intermediários financeiros para amenizar esses problemas, uma vez que esses são mais bem equipados do que agentes individuais para distinguir os riscos de créditos ruins dos bons, bem como criar um aparato para monitorar as ações dos tomadores de crédito. Assim, intermediários financeiros tendem a melhorar o bom funcionamento do mercado financeiro, facilitando a transferência de poupança entre emprestador e tomador de crédito, o que tende a gerar, como resultado final, aumento de recursos para o setor produtivo, ocasionando crescimento econômico.

Segundo Becsi e Wang (1997), o canal de transmissão ou de conexão entre o crescimento econômico e sistema financeiro reside no fato que esse último pode aumentar tanto a quantidade quanto a qualidade do investimento agregado. O processo de intermediação amplia a probabilidade da realização de investimentos mais lucrativos. O aumento da quantidade dos investimentos se deve às economias de escala, visto que o sistema financeiro reduz os custos envolvidos em uma transação financeira e, dessa forma, consegue captar mais recursos que podem ser utilizados em investimentos no setor privado. A qualidade dos investimentos é ampliada com a intermediação financeira porque o intermediário está mais disposto a financiar projetos que são mais arriscados ${ }^{7}$ (possuem uma rentabilidade esperada mais elevada) do que um poupador individual, pois este último possui o perfil de ser avesso ao risco. O intermediário financeiro se beneficia de sua escala de produção (especialização), visto que essa lhe permite diversificar sua carteira de investimentos, diluindo o risco a níveis razoáveis.

Outro canal pelo qual o sistema financeiro pode promover o crescimento é proporcionando às famílias menos abastadas recursos para acumulação de capital humano, ${ }^{8}$ pois, de outra forma, essas famílias não teriam acesso à educação, por ser a educação um bem caro. Assim, tanto por reduzir a necessidade de liquidez das firmas como por resolver o problema de indivisibilidade de alguns investimentos, quanto por facilitar a acumulação de capital (físico e humano), o sistema financeiro contribui para criar um ambiente mais propenso ao crescimento econômico.

Dada a importância de um sistema financeiro no estímulo ao processo produtivo de uma economia, é relevante listar algumas das principais funções desse setor. A próxima seção aborda este tema.

6 Arkelof (1970) foi o primeiro a formalizar o problema de seleção adversa. Em seu famoso artigo "The market for 'lemons': quality, uncertainty and market mechanism" expôs o funcionamento do mercado de carros usados quando há assimetria de informação. Dado que o comprador não consegue distinguir um carro de boa qualidade de um de má qualidade, ele vai querer pagar um preço médio, o qual está entre o valor do carro de má e boa qualidade. Isto causaria, segundo o autor, um aumento da oferta dos carros de má qualidade e uma diminuição da oferta de carros de alta qualidade. No limite, o mercado terá somente carros de baixa qualidade.

7 Por exemplo, investimento em Pesquisa \& Desenvolvimento (P\&D). Este necessita grandes volumes de recursos, bem como um longo período de maturação. Contudo, quando este obtém sucesso, sua rentabilidade é elevada se comparada a investimentos tradicionais, pois, segundo a Teoria do Crescimento Endógeno, o inventor terá poder de monopólio (patente) pela sua invenção por um determinado período de tempo. Neste sentido, é praticamente improvável que um poupador individual empreste para esta firma, pois seu horizonte temporal é mais limitado, ou seja, sua taxa de impaciência é elevada, o que não lhe permite esperar um período grande para a maturação dos investimentos em P\&D. Já intermediários financeiros são mais propensos a conceder empréstimos com tal finalidade, pois sua carteira de investimentos permite tal concessão de crédito. Além do mais, por definição, uma instituição financeira pode ter "vida" infinita, o que não ocorre com os indivíduos.

8 Segundo Lucas (1988), os indivíduos acumulam capital humano tal como acumulam capital físico, sendo os dois tipos de capital fatores determinantes do crescimento da economia. 


\section{FUNÇÕES DO SISTEMA FINANCEIRO}

A seção anterior expôs o cenário econômico no qual o sistema financeiro está incluído. Percebe-se que o mundo real é caracterizado pela presença de assimetria de informação e poder de mercado, o que dificulta a alocação eficiente dos recursos financeiros, caso não haja um intermediário financeiro entre poupador e investidor. Listam-se, a seguir, algumas funções do sistema financeiro que lhe conferem a capacidade para promover a eficiência alocativa dos recursos financeiros. São elas: a) mobilização de recursos; b) alocação dos recursos no espaço e no tempo; c) administração do risco; d) seleção e monitoração de empresas; e e) produção e divulgação de informação. Abaixo, descreve-se cada uma dessas funções:

\section{a) Mobilização de recursos}

Compreende a função de agregação de poupanças individuais. Com esta função, o sistema financeiro permite aos investidores individuais o financiamento completo de seus projetos. Não havendo intermediação por parte de bancos ou outros participantes do sistema financeiro, o investidor estaria restrito a um projeto passível de implementação somente com seus recursos próprios. Assim, investimentos que necessitassem de grandes volumes de recursos só poderiam ser implementados por pouquíssimas famílias abastadas, ou seja, reduziria muito a probabilidade do investimento ser efetivado, pois nem todas as famílias ricas possuem interesse em produzir ou mesmo possuem o espírito empreendedor. Segundo Carvalho (2002), para que as firmas alcancem escalas economicamente eficientes é essencial que tenham acesso à poupança de vários indivíduos, situação perfeitamente compatível com a intermediação financeira.

\section{b) Alocação dos recursos no espaço e no tempo}

Refere-se à importante função de fornecer recursos a projetos de longa duração. Os indivíduos que poupam possuem um horizonte de curto prazo, o que lhes confere um perfil de concessão de empréstimos de alta liquidez, isto é, eles podem desejar converter seus empréstimos em moeda em um período pequeno de tempo. No entanto, investimentos ${ }^{10}$ que criam maiores retornos necessitam de um período maior de maturação. Forma-se, deste modo, um conflito de interesses. O sistema financeiro atua no sentido de intermediar essas transações, pois ele capta o depósito do poupador, garantindo-lhe o direito a liquidez, e empresta ao investidor a prazo mais elástico. Esse sistema torna-se mais eficiente quanto maior o número de transações realizadas pelo intermediário financeiro.

\section{c) Administração do risco}

Os intermediários financeiros figuram como os agentes mais preparados para minimizar os riscos que envolvem as transações financeiras. Isto ocorre devido à diversificação da carteira de concessão de crédito aos diferentes tipos de riscos envolvidos em cada atividade produtiva. Dito em outras palavras, o sistema financeiro busca se proteger dos riscos emprestando a diferentes firmas e setores, pois alguns projetos fracassarão e outros serão bem-sucedidos, mas, na média, o resultado será positivo. Segundo Bebczuk (2003), os agentes enfrentam dois tipos de riscos: risco idiossincrático e risco sistemático. O primeiro pode ser entendido como inerente à natureza do projeto, o qual pode ser mensurado pela incerteza quanto ao retorno desse projeto após a maturação do

9 Isso ocorre porque os indivíduos são avessos ao risco, motivo pelo qual poupam. Assim, para se protegerem de eventuais adversidades futuras, buscam não emprestar seus recursos a prazo muito longo, pois sua função-utilidade valoriza mais sua liquidez do que a incerteza de um retorno maior no futuro distante.

10 Investimento no sentido de investir no setor produtivo da economia. Aplicação no sistema financeiro (por exemplo, aplicações em CDB) não está inclusa no conceito de investimento. 
investimento. A melhor maneira de minimizar os problemas decorrentes deste tipo de risco é via diversificação de investimentos, pois esta funciona como redutor de custos idiossincráticos, porque, na agregação dos investimentos, o retorno esperado é preservado positivo. O segundo refere-se a situações adversas que podem ocorrer com ambos os tipos de investimentos, sendo a probabilidade de ocorrência igual para todos. ${ }^{11}$ Assim, uma forma de minimizar esse risco é garantir maior liquidez aos investimentos, para que haja recursos para eventuais necessidades.

d) Seleção e monitoração de empresas

O sistema financeiro possui a importante função de selecionar e monitorar as empresas que possuem as melhores propostas de investimento produtivo. Esta função é exercida, primordialmente, pelos intermediários financeiros, uma vez que estes estão mais bem equipados do que agentes individuais, pois estes últimos não têm o conhecimento técnico necessário, bem como a escala ótima que lhes permitiria selecionar e monitorar as empresas ou investidores a um custo economicamente suportável. Portanto, por causa das economias de escala, o sistema financeiro pode coletar um grande número de informação, ${ }^{12}$ adquirir especialização e criar condições críveis para monitorar as ações dos tomadores de crédito, com o intuito de garantir que o principal e os juros sejam pagos.

\section{e) Produção e divulgação de informação}

A informação é um bem extremamente importante quando se consolida uma transação, seja ela financeira ou não. A presença de informação assimétrica causa desvantagens para a parte que estiver menos informada, pois a parte mais informada pode utilizar a informação que possui a mais para seu próprio proveito, e isto pode gerar ineficiência econômica. A assimetria de informação, como visto anteriormente, pode ocasionar problemas de seleção adversa e de risco moral, problemas que podem até mesmo colapsar o mercado de crédito. Com a atuação do sistema financeiro, esses problemas são minimizados, permitindo o funcionamento a contento do mercado de crédito. Entretanto, a informação gerada pelo setor financeiro tende a transcender os problemas de seleção adversa e risco moral pertencentes às duas partes da transação financeira (poupador e tomador de empréstimo), pois o mercado como um todo se beneficia. Por exemplo, quando um banco concede um empréstimo para uma determinada empresa, ele não só está fornecendo liquidez para a firma (a qual investirá na ampliação da capacidade produtiva) como também está sinalizando, indiretamente, para o mercado que esta firma está "saudável” economicamente, uma vez que o banco analisou seu projeto e concedeu empréstimo. Neste sentido, o sistema financeiro poderia ser pensado como um indicador de qualidade de firmas. ${ }^{13}$

\section{DESENVOLVIMENTO FINANCEIRO E CRESCIMENTO ECONÔMICO: EVIDÊNCIAS EM- PÍRICAS}

As seções anteriores mostraram, de forma esquemática, os insights teóricos sobre a relevância do sistema financeiro no processo de alocação dos recursos para a acumulação de capital físico e humano, os quais são variáveis importantes para a determinação do crescimento econômico. O

11 Por exemplo, tome-se o caso de um raio que cai em determinado lugar. A probabilidade de este cair em uma determinada empresa é a mesma de cair na empresa do lado, ou mesmo nas empresas que estão situadas a um raio de três quarteirões (supondo que ambas possuem pára-raios semelhantes). Assim, todas estão sujeitas às mesmas adversidades.

12 Com o tempo, os intermediários financeiros podem construir séries históricas, podendo cruzar as informações antigas com as informações atuais, provendo uma melhor visualização das atividades econômicas e das empresas.

13 Esta análise poder ser também estendida para os consumidores. Entretanto, está-se interessado no lado da oferta, que é responsável pelo crescimento no longo prazo.

Econ. Aplic., 10(3): 425-442, jul-set 2006 
objetivo neste trabalho é exatamente testar as predições da teoria que associa desenvolvimento financeiro ao crescimento econômico.

Para tal propósito, utiliza-se a técnica de Regressão Quantílica, ${ }^{14}$ a qual permite analisar a associação contemporânea entre a variável resposta (medidas de crescimento econômico) com as variáveis explicativas (medidas de desenvolvimento financeiro) nos diversos quantis da distribuição condicional. Assim, obtém-se um mapeamento mais completo do impacto do desenvolvimento financeiro sobre o crescimento econômico, pois se consegue investigar como cada quantil responde, em vez de se ter somente uma reta de regressão para o caso da média. Algumas vantagens inerentes à regressão quantílica sobre os MQO podem ser listadas da seguinte forma (Koenker e Bassett, 1978):

- A técnica de regressão quantílica permite caracterizar toda distribuição condicional de uma variável resposta a partir de um conjunto de regressores;

- Regressão quantílica pode ser usada quando a distribuição não é gaussiana;

- Regressão quantílica usa a totalidade dos dados para estimar os coeficientes angulares dos quantis, ou seja, não há subamostras do conjunto de dados;

- Regressão quantílica é robusta a outliers;

- Por utilizar a distribuição condicional da variável resposta, podem ser estimados os intervalos de confiança dos parâmetros e do regressando diretamente dos quantis condicionais desejados;

- Como os erros não possuem uma distribuição normal, os estimadores provenientes da regressão quantílica podem ser mais eficientes que os estimadores por meio de MQO;

- A regressão quantílica pode ser representada como um modelo de programação linear, o que facilita a estimação dos parâmetros. Muitos pacotes econométricos já possuem comandos próprios para esta finalidade, tais como S-PLUS, Stata, SHAZAM, entre outros.

Regressão quantílica pode ser vista como uma extensão natural dos quantis amostrais para o caso de um modelo linear $y_{t}=X_{t} \beta+\varepsilon_{t}$, que assume a seguinte forma:

$$
\min _{b \in \mathfrak{R}} n^{-1}\left\{\sum_{t \in\left\{t: y_{t} \geq x_{t} \beta\right\}} \theta\left|y_{t}-x_{t} \beta\right|+\sum_{t \in\left\{t: y_{t} \geq x_{t} \beta\right\}}(1-\theta)\left|y_{t}-x_{t} \beta\right|\right\}=\min n^{-1} \sum_{i=1}^{n} \rho_{\theta}\left(y_{t}-x_{t} \beta\right)
$$

em que $\rho$ é a função "check” definida por

$$
\rho_{\theta}(u)= \begin{cases}\theta u, & u \geq 0 \\ (\theta-1) u, & u<0\end{cases}
$$

em que a função $\rho_{\theta}$ multiplica os resíduos por $\theta$, se eles forem não-negativos e por $(\theta-1)$, caso contrário, para que, dessa forma, sejam tratados assimetricamente.

14 Apesar de a Regressão Quantílica ter sido inventada há mais de 25 anos, são poucos os trabalhos que utilizam esta técnica, evidenciando o grande potencial ainda não explorado. Em crescimento econômico, é muito pequena a utilização de regressão quantílica, motivo pelo qual este trabalho a utiliza. 


\section{BASE DE DADOS E RESULTADOS}

O objetivo empírico deste trabalho é analisar se há uma relação positiva entre desenvolvimento financeiro e crescimento econômico nos diversos quantis da distribuição condicional da variável resposta. Para tal, utilizam-se duas medidas para representar a variável independente (desenvolvimento financeiro) e duas medidas para indicar a variável dependente (crescimento econômico). As medidas são:

\section{a) Desenvolvimento financeiro}

a.1) Medida de intensidade financeira (IF), financial depth, a qual pode ser entendida como o tamanho do setor de intermediação financeira formal. Esta variável é medida a partir dos exigíveis de curto prazo do sistema financeiro como uma fração do PIB. Se o sistema financeiro desempenha as funções descritas neste trabalho, então se espera que a relação desta variável com as medidas de crescimento econômico seja positiva. A intuição de se utilizar a variável intensidade financeira reside no fato de os intermediários financeiros captarem recursos de curto prazo, convertendo-os em empréstimos de longo prazo, beneficiando o crescimento econômico, pois assim permitem às firmas um horizonte de investimento mais longo, além de garantir a liquidez dos depositantes;

a.2) Participação do crédito dos bancos comerciais em relação ao total de crédito doméstico (BANCO), este último entendido como a soma do crédito provido pelo banco central e demais bancos. Aqui se supõe que os bancos comerciais são mais eficientes na alocação dos recursos financeiros do que o banco central. Neste sentido, quanto maior o volume de crédito dos bancos comerciais em relação ao total de crédito doméstico, mais eficiente o mercado de crédito se torna, tendendo a aumentar a capacidade produtiva da economia. Portanto, a relação é positiva com o crescimento econômico.

\section{b) Crescimento econômico}

Ambas as medidas de crescimento econômico são correspondentes aos 77 países que compõem a amostra deste trabalho. Estas são referentes ao período de 1980 a 1992 e foram obtidas a partir do banco de dados da Summers-Heston.

b.1) Taxa de crescimento real média do PIB per capita (PIB). Esta foi calculada como a taxa de crescimento geométrica;

b.2) Taxa de crescimento real média do capital per capita (CAPITAL). Esta foi calculada como coeficiente de regressão por mínimos quadrados ordinários.

Além das variáveis listadas acima, também utilizou-se um conjunto de variáveis para controlar características individuais de cada uma das 77 nações, pois outros fatores podem ter efeito sobre a variável crescimento econômico. Entre estas variáveis estão: a) PIB real per capita em $1980,{ }^{15}$ usando dados de Summers-Heston; b) taxa de inflação, definida em logaritmo natural; c) comércio internacional médio para o período de 1980 a 1995, definido como a proporção das importações mais as exportações sobre o PIB; e d) crescimento da escolaridade, medido como a diferença (em log) dos anos de estudo da década de 1990 para a década de 1980, para um indivíduo de 25 anos de idade.

A escolha desse conjunto de variáveis de controle se justifica por serem estas amplamente utilizadas em trabalhos empíricos. Somente para citar alguns trabalhos que foram utilizados no

15 A última variável também permite testar a hipótese de convergência, questão esta que despertou muito interesse por parte dos pesquisadores nas décadas de 1980 e 1990, tendo como resultado um grande volume de trabalhos teórico e empírico. Ver Baumol et al. (1994). 
processo de seleção das variáveis, temos: Baumol et al. (1994); Barro (1991); Mankiw et al. (1992), Bebczuk (2001), Levine et al. (2002), Barreto et al. (2004), entre outros. Cabe salientar ainda que todos os dados foram obtidos da mesma base de dados (Summers-Heston), garantindo, assim, uniformidade metodológica. ${ }^{16}$

A estimação dos resultados neste trabalho se dá em duas etapas. A primeira não utiliza as variáveis de controle (PIB inicial, taxa de inflação, comércio internacional e escolaridade). Na segunda etapa, tais variáveis são incluídas, com o intuito de verificar quão sensíveis são as variáveis de interesse (medidas do desenvolvimento financeiro) quando são controladas características individuais dos países.

A Tabela 1 mostra as estimativas obtidas pelo método de Mínimos Quadrados Ordinários (MQO) e Regressão Quantílica (RQ). A variável explicativa de interesse é a medida de intensidade financeira (IF) e como variáveis dependentes a taxa de crescimento real do PIB per capita (PIB) e a taxa de crescimento real do capital per capita (CAPITAL).

Tabela 1 - Resultados por MQO e RQ. Variável explicativa: intensidade financeira

\begin{tabular}{lcccccc}
\hline Variável Dependente & $\mathrm{MQO}$ & $\mathrm{RQ}$ & $\mathrm{RQ}$ & $\mathrm{RQ}$ & $\mathrm{RQ}$ & $\mathrm{RQ}$ \\
& & 0,1 & 0,25 & 0,5 & 0,75 & 0,9 \\
\hline Taxa de crescimento real do PIB & $.0379723^{*}$ & .0330522 & $.0393209^{*}$ & $.0455272^{*}$ & $.0307359^{*}$ & $.0390612^{\star *}$ \\
per capita & $(.0066534)$ & $(.0306141)$ & $(.0118841)$ & $(.0058049)$ & $(.0075574)$ & $(.0170946)$ \\
Taxa de crescimento real do & $.0350952^{*}$ & $.0472281^{* * *}$ & $.0383212^{*}$ & $.0380457^{*}$ & $.0279687^{* *}$ & .0216139 \\
capital per capita & $(.0084814)$ & $(.0292561)$ & $(.0146699)$ & $(.0048689)$ & $(.0146657)$ & $(.0226384)$ \\
\hline
\end{tabular}

Fonte: Elaboração dos autores.

Nota: coeficientes em negrito e desvios padrão entre parênteses.

* significante ao nível de 1\%; ** significante ao nível de 5\%; *** significante ao nível de $10 \%$.

Na Tabela 1 percebe-se que os sinais dos coeficientes se comportam como o esperado, ou seja, a intensidade da atividade do sistema financeiro impacta positivamente as medidas de crescimento econômico. $\mathrm{O}$ aspecto da assimetria na resposta da variável dependente às variáveis explicativas também foi confirmada pelos dados, visto que, para o caso da taxa de crescimento do PIB per capi$t a$, a medida de desenvolvimento financeiro teve efeito positivo da ordem de 3,07\% no quantil 0,75 e um efeito de $4,55 \%$ para o caso da mediana (quantil 0,50 ).

16 Ao proceder a uma investigação que busca comparar um conjunto grande de países, diferentes em relação aos aspectos econômicos e regionais, é imprescindível utilizar uma metodologia universal para todos os países. Caso contrário, a análise pode perder sua validade. Neste sentido, para contornar este problema foi utilizada a base de dados de Summers-Heston, que vem sendo amplamente utilizada em trabalho empíricos desde o final dos anos 1980. 
Figura 2 - Crescimento real do PIB per capita e intensidade financeira

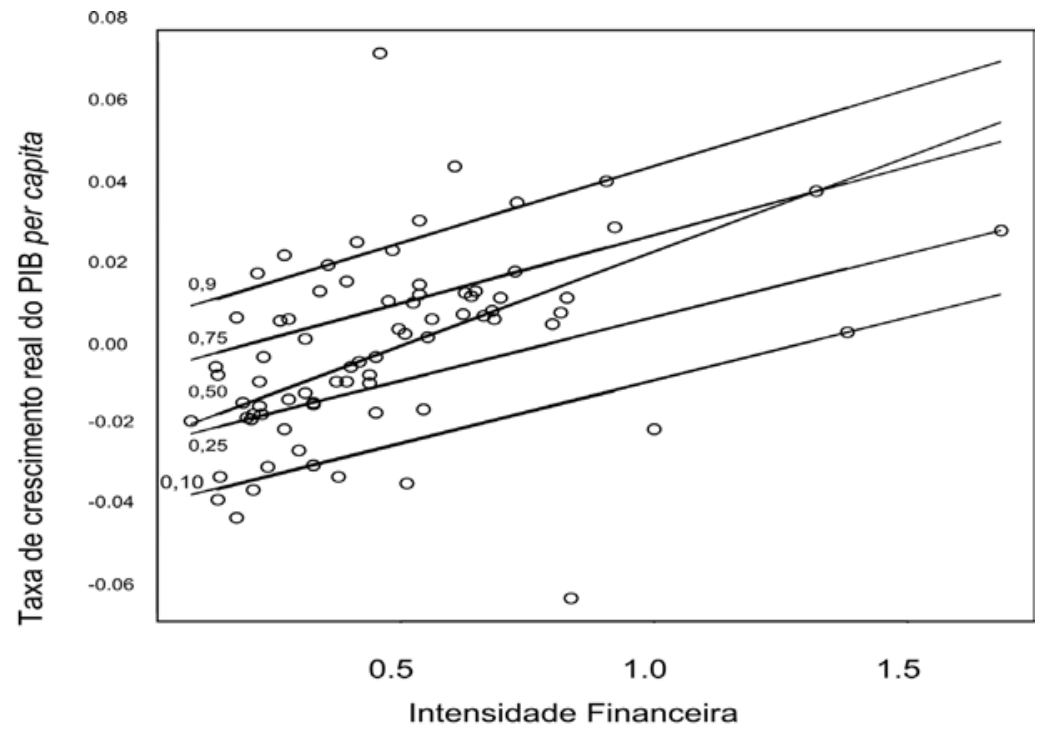

Fonte: Elaboração dos autores

A assimetria ainda é mais forte no caso da taxa real de crescimento do capital per capita (ver Tabela 1 e Figura 3), a qual varia de 2,79\% (quantil 0,75) e 4,72\% (quantil 0,10). Se se procedesse somente a uma análise mais simples, empregando o método de MQO, ter-se-ia um valor de 3,79\%, no caso da taxa de crescimento do PIB per capita, e 3,5\%, no caso da taxa de crescimento do capital per capita, para todos os países, tanto os que cresceram mais rápido (quantis mais elevados) quanto os que cresceram a taxas menores (quantis mais baixos). As Figuras 2 e 3 mostram as retas de regressão para os quantis condicionais. Percebe-se que em ambas as figuras a assimetria na resposta da variável dependente para a variável explicativa é uma característica marcante.

Figura 3 - Taxa de crescimento real per capita do capital e intensidade financeira

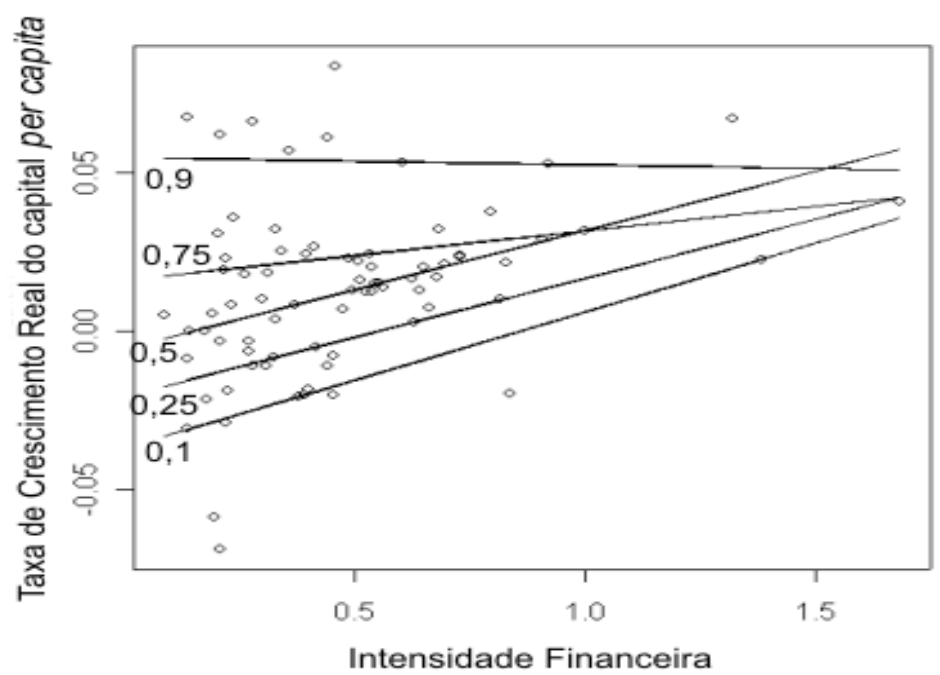

Fonte: Elaboração dos autores. 
Tabela 2 - Resultados por MQO e RQ. Variável explicativa: proporção do crédito bancário em relação ao crédito total doméstico

\begin{tabular}{lcccccc}
\hline Variável Dependente & $\mathrm{MQO}$ & $\mathrm{RQ}$ & $\mathrm{RQ}$ & $\mathrm{RQ}$ & $\mathrm{RQ}$ & $\mathrm{RQ}$ \\
& & 0,1 & 0,25 & 0,5 & 0,75 & 0,9 \\
\hline Taxa de crescimento real do PIB & $.061055^{*}$ & $.052213^{* *}$ & $.0633252^{*}$ & $.0501281^{*}$ & $.0574382^{*}$ & $.0748966^{* *}$ \\
per capita & $(.0103367)$ & $(.0277655)$ & $(.0171682)$ & $(.0074184)$ & $(.016316)$ & $(.0350538)$ \\
Taxa de crescimento real do & $.0533508^{*}$ & $.1058324^{*}$ & $.0678077^{\star}$ & $.0483281^{*}$ & $\mathbf{0 . 0 3 4 9 0 8 2}$ & $\mathbf{0 . 0 3 3 9 5 2 4}$ \\
capital per capita & $(.0135673)$ & $(.0336162)$ & $(.0189096)$ & $(.013972)$ & $(.0273546)$ & $(.0290882)$ \\
\hline
\end{tabular}

Fonte: Elaboração dos autores.

Nota: coeficientes em negrito e desvios padrão entre parênteses.

* significante ao nível de 1\%; ** significante ao nível de 5\%; *** significante ao nível de $10 \%$.

Figura 4 - Taxa de crescimento real do capital per capita e proporção do crédito bancário em relação ao crédito total

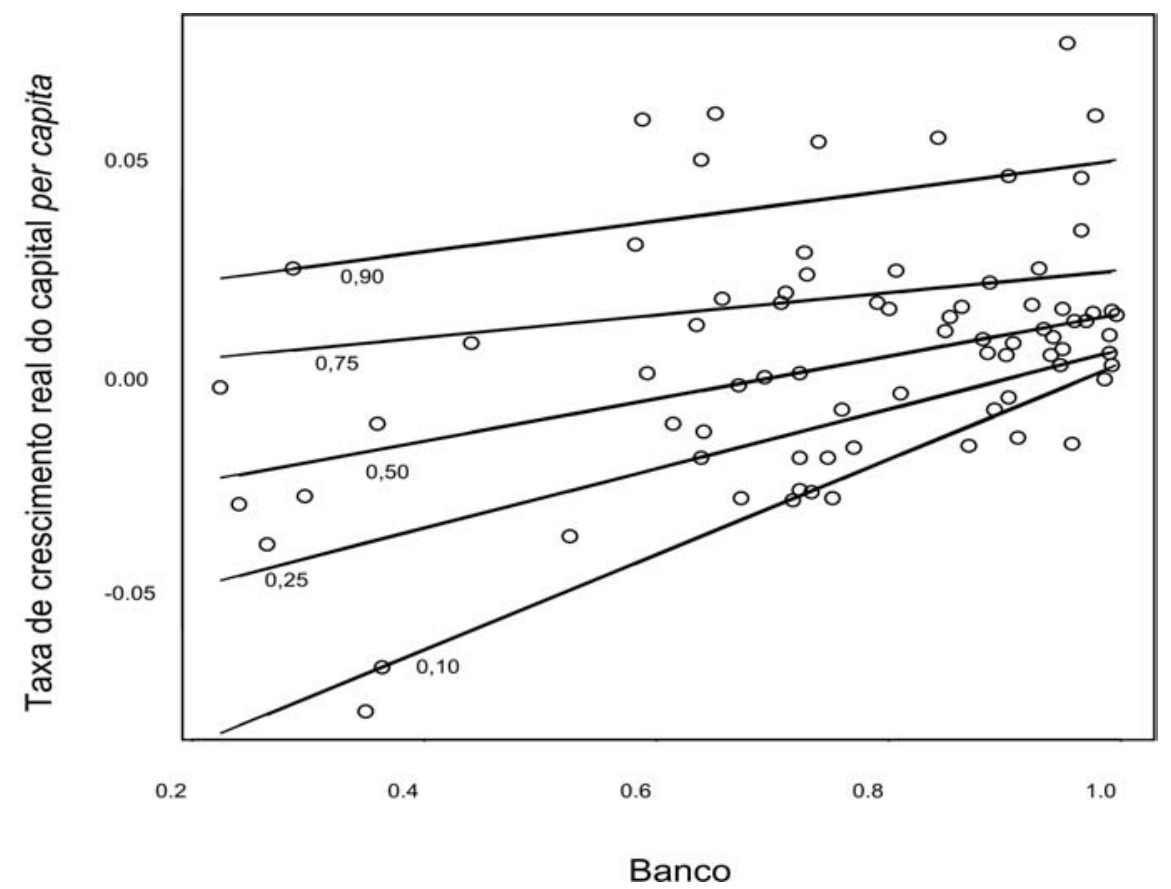

Fonte: Elaboração dos autores.

Quando se analisa a variável crédito bancário como proporção do crédito doméstico (BANCO) também encontra-se uma relação positiva com as medidas de crescimento econômico (ver Tabela 2). Entretanto, quando se investiga o impacto da variável explicativa sobre a taxa de crescimento do capital per capita, dois quantis não são significativos estatisticamente, ${ }^{17}$ quantis 0,75 e 0,90. Nas duas medidas de crescimento econômico, a variável independente afetou de forma assimétrica (ver Figuras 4 e 5), corroborando a hipótese de que países com diferentes magnitudes de crescimento respondem diferentemente ao desenvolvimento financeiro.

17 No caso da medida de intensidade financeira, somente um quantil não foi significativo estatisticamente: quantil 0,90 . 
Figura 5 - Taxa de crescimento real do PIB per capita e proporção do crédito bancário em relação ao crédito total

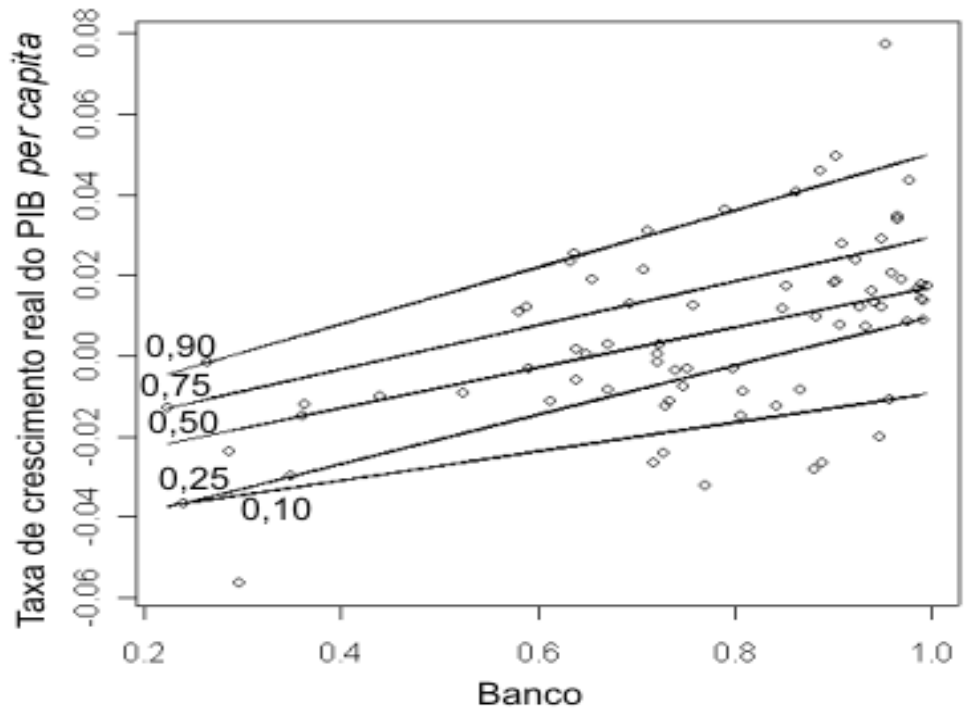

Fonte: Elaboração dos autores.

Os modelos analisados até agora estimaram a relação entre as varáveis de crescimento econômico e as variáveis de desenvolvimento do sistema financeiro, porém não foram controlados outros fatores que também influenciam o crescimento econômico, como a literatura sugere. Sem tal controle, as estimativas do efeito das medidas de desenvolvimento financeiro podem estar captando outros efeitos que não seus próprios. ${ }^{18}$ No sentido de tentar mitigar tal problema, são acrescentadas nos dois modelos construídos acima (Tabelas 1 e 2) variáveis de controle, como taxa de inflação, comércio internacional, renda per capita inicial e crescimento da educação.

Quando são controladas as características individuais entre países, as evidências, mesmo assim, são persistentes. Em valores absolutos, houve um aumento do impacto da variável BANCO sobre as medidas de crescimento quando se controlaram fatores individuais das nações, sendo que ocorreu o inverso no caso da variável intensidade financeira (IF), que teve seus coeficientes diminuídos, em valores absolutos.

O único quantil que apresentou coeficiente negativo foi o quantil 0,10 no modelo taxa de crescimento do PIB e a variável explicativa IF, mas não foi estatisticamente significativo. Ainda analisando este modelo, a assimetria na resposta da distribuição condicional da variável taxa de crescimento do PIB foi minimizada, sendo que todos os quantis estatisticamente significativos ficaram na casa dos $2 \%(2,1 \%$ a 2,69\%). A variabilidade nos quantis condicionais é maior no modelo em que a taxa de crescimento do capital é a variável dependente. Esta varia entre 1,29 (quantil 0,10) a 2,66 (quantil 0,25).

18 Outra provável vantagem de adicionar as variáveis de controle é a de contornar o possível problema de viés por omissão de variáveis relevantes no modelo analisado. Ver Wooldridge (2000). 
Tabela 3 - Resultados por MQO e RQ. Variável explicativa: intensidade financeira. Variáveis de controle: taxa de inflação, comércio internacional, renda per capita inicial e crescimento da educação

\begin{tabular}{|c|c|c|c|c|c|c|}
\hline \multirow{2}{*}{$\begin{array}{l}\text { Variável dependente: Taxa de crescimento } \\
\text { real do PIB per capita }\end{array}$} & \multirow[t]{2}{*}{ MQO } & $\mathrm{RQ}$ & $R Q$ & $R Q$ & $R Q$ & $R Q$ \\
\hline & & 0,1 & 0,25 & 0,5 & 0,75 & 0,9 \\
\hline \multirow[t]{2}{*}{ Intensidade Financeira } & $.02092^{* *}$ & -.00012 & $.021018^{*}$ & $.024277^{*}$ & $.026969^{*}$ & .0343653 \\
\hline & $(.009625)$ & $(.02099)$ & $(.006330)$ & $(.007083)$ & $(.012084)$ & $(.030634)$ \\
\hline \multirow[t]{2}{*}{ Taxa de Inflação } & $-.02918^{*}$ & $-.042^{* * *}$ & $-.03476^{*}$ & $-.02462^{*}$ & -.02753 & -.031205 \\
\hline & $(.011719)$ & $(.02537)$ & $(.008050)$ & $(.009048)$ & $(.02057)$ & $(.033720)$ \\
\hline \multirow[t]{2}{*}{ Comércio internacional } & -.000001 & -.00008 & -.00003 & $.000057^{*}$ & .0000508 & -.000015 \\
\hline & $(.000048)$ & $(.00012)$ & $(.000031)$ & $(.000029)$ & $(.000056)$ & $(.000139)$ \\
\hline \multirow[t]{2}{*}{ Renda per capita inicial } & .0042683 & .010921 & $.005721^{*}$ & $.00396^{\star *}$ & -.00071 & -.001686 \\
\hline & $(.003184)$ & $(.00906)$ & $(.002072)$ & $(.002272)$ & $(.004452)$ & $(.008242)$ \\
\hline \multirow[t]{2}{*}{ Crescimento da educação } & .0007857 & -.00062 & -.00030 & $.002315^{*}$ & .0001756 & .0013128 \\
\hline & $(.001471)$ & $(.00454)$ & $(.001039)$ & $(.001048)$ & $(.001782)$ & $(.004607)$ \\
\hline \multirow{2}{*}{$\begin{array}{l}\text { Variável dependente: Taxa de crescimento } \\
\text { real do PIB per capita }\end{array}$} & MQO & $\mathrm{RQ}$ & $\mathrm{RQ}$ & $R Q$ & $R Q$ & $R Q$ \\
\hline & & 0,1 & 0,25 & 0,5 & 0,75 & 0,9 \\
\hline \multirow[t]{2}{*}{ Intensidade Financeira } & .0182796 & $.01299^{* *}$ & $.026639^{*}$ & $.022565^{\star}$ & $.02006^{* *}$ & .017994 \\
\hline & $(.012204)$ & $(.007366)$ & $(.006551)$ & $(.009127)$ & $(.010679)$ & $(.044005)$ \\
\hline \multirow[t]{2}{*}{ Taxa de Inflação } & $-.03306^{*}$ & $-.07191^{*}$ & $-.01625^{*}$ & -.013633 & $-.0252^{* *}$ & -.027916 \\
\hline & $(.014859)$ & $(.013702)$ & $(.008158)$ & $(.010462)$ & $(.014896)$ & $(.035427)$ \\
\hline \multirow[t]{2}{*}{ Comércio internacional } & .0000601 & -.000047 & $.000047^{*}$ & $.00010^{* *}$ & $.000092^{*}$ & .0000431 \\
\hline & $(.000061)$ & $(.000031)$ & $(.000030)$ & $(.000046)$ & $(.000042)$ & .0000918 \\
\hline \multirow[t]{2}{*}{ Renda per capita inicial } & .0038024 & $.013305^{\star}$ & $.011746^{*}$ & $.00571^{* *}$ & $-.00832^{*}$ & -.015475 \\
\hline & $(.004037)$ & $(.003713)$ & $(.002261)$ & $(.002945)$ & $(.003830)$ & .0147123 \\
\hline \multirow[t]{2}{*}{ Crescimento da educação } & $.00319^{\star *}$ & .0020174 & $.003070^{*}$ & .0016561 & -.000364 & .0024186 \\
\hline & $(.001865)$ & $(.002113)$ & $(.001081)$ & $(.001367)$ & $(.001669)$ & .0046688 \\
\hline
\end{tabular}

Fonte: Elaboração dos autores.

Nota: coeficientes em negrito e desvios padrão entre parênteses.

* significante ao nível de $1 \%$; ** significante ao nível de 5\%; *** significante ao nível de $10 \%$.

Outra característica importante que a Tabela 3 possibilita inferir é que, quanto maior a taxa de crescimento do PIB, maior é o impacto positivo da variável IF, reforçando a argumentação teórica de que o sistema financeiro tem um papel decisivo no crescimento econômico. Esta tendência não é plenamente verificada quando se utiliza a taxa de crescimento do capital como variável dependente. Como pode ser visto na Tabela 3, há uma tendência crescente no valor do coeficiente do quantil 0,10 para o quantil 0,25, mas esta tendência é interrompida a partir do quantil 0,50, sinalizando declínio no valor absoluto dos demais coeficientes. Contudo, mesmo declinando, estes ainda são maiores do que o quantil 0,10 . 
Tabela 4 - Resultados por MQO e RQ. Variável explicativa: proporção do crédito bancário em relação ao crédito total doméstico. Variáveis de controle: taxa de inflação, comércio internacional, renda per capita inicial e crescimento da educação

\begin{tabular}{lcccccc}
\hline $\begin{array}{l}\text { Variável dependente: Taxa de crescimento } \\
\text { real do Capital per capita }\end{array}$ & $\mathrm{MQO}$ & $\mathrm{RQ}$ & $\mathrm{RQ}$ & $\mathrm{RQ}$ & $\mathrm{RQ}$ & $\mathrm{RQ}$ \\
& & 0,1 & 0,25 & 0,5 & 0,75 & 0,9 \\
\hline Banco & $.04866^{*}$ & .0300953 & .0235442 & $.056881^{*}$ & $.05636^{* *}$ & .0719353 \\
& $(.01515)$ & $(.036852)$ & $(.01973)$ & $(.016469)$ & $(.024724)$ & $(.052522)$ \\
Taxa de Inflação & $-.028^{* *}$ & $-.04872^{*}$ & $-.03958^{*}$ & -.010416 & -.020072 & -.025397 \\
& $(.01174)$ & $(.018606)$ & $(.013158)$ & $(.011653)$ & $(.018213)$ & $(.021356)$ \\
Comércio internacional & -.00010 & $-.0003^{* * *}$ & $-.0002^{* *}$ & -.000045 & $(.000049)$ & .0000992 \\
& $(.00006)$ & $(.000146)$ & $(.000077)$ & $(.000069)$ & $(.000118)$ & $(.000147)$ \\
Renda per capita inicial & .000967 & .0077108 & .0043602 & .0008575 & -.005979 & -.007295 \\
& $(.00318)$ & $(.010102)$ & $(.003329)$ & $(.003276)$ & $(.004697)$ & $(.007442)$ \\
Crescimento da educação & .001134 & .001816 & -.000302 & .0012663 & -.000365 & .0007271 \\
& $(.00141)$ & $(.002521)$ & $(.001275)$ & $(.001537)$ & $(.001984)$ & $(.004217)$ \\
\hline Variável dependente: Taxa de crescimento & $\mathrm{MQO}$ & $\mathrm{RQ}$ & $\mathrm{RQ}$ & $\mathrm{RQ}$ & $\mathrm{RQ}$ & $\mathrm{RQ}$ \\
real do Capital per capita & & 0,1 & 0,25 & 0,5 & 0,75 & 0,9 \\
& & & & & \\
\hline Banco & $.053130^{*}$ & $.038096^{*}$ & .0229577 & $.073949^{*}$ & $.06051^{* *}$ & $.089896^{*}$ \\
& $(.02008)$ & $(.015268)$ & $(.014864)$ & $(.011071)$ & $(.025979)$ & $(.028216)$ \\
Taxa de Inflação & $-.025^{* \star *}$ & $-.04535^{*}$ & -.015548 & $-.02674^{*}$ & $-.041^{* * *}$ & -.02756 \\
& $(.015560)$ & $(.009478)$ & $(.010066)$ & $(.007834)$ & $(.021547)$ & $(.019049)$ \\
Comércio internacional & .0000363 & $-.0001^{* *}$ & .0000215 & -.000012 & -.00003 & -.000018 \\
& $(.000084)$ & $(.000045)$ & $(.000064)$ & $(.000047)$ & $(.000115)$ & $(.000200)$ \\
Renda per capita inicial & .0003767 & $.012881^{*}$ & $.012276^{*}$ & $-.0053^{* *}$ & $-.01687^{*}$ & $-.02024^{*}$ \\
Crescimento da educação & $(.004221)$ & $(.002063)$ & $(.003453)$ & $(.0025)$ & $(.005354)$ & $(.006076)$ \\
& $.00392^{* *}$ & $.0034^{* * *}$ & .0019746 & $.0032^{*}$ & .001562 & .0028645 \\
& $(.001866)$ & $(.001938)$ & $(.001651)$ & $(.001111)$ & $(.002171)$ & $(.003233)$ \\
\hline
\end{tabular}

Fonte: Elaboração dos autores.

Nota: coeficientes em negrito e desvios padrão entre parênteses.

* significante ao nível de 1\%; ** significante ao nível de 5\%; *** significante ao nível de $10 \%$.

Quando as variáveis de controle são consideradas na análise (Tabela 3), ${ }^{19}$ estas assumem os sinais convencionais sugeridos pela literatura, ou seja, taxa de inflação se relaciona negativamente com crescimento econômico; comércio internacional e o crescimento da educação contribuem positivamente para o crescimento econômico; renda per capita inicial também apresenta coeficiente angular positivo, indicando que não há convergência entre os países. ${ }^{20}$

19 A análise só se ateve aos coeficientes angulares estatisticamente significativos, com nível de significância de no máximo $10 \%$. Uma das razões para a presença de estimativas não significativas estatisticamente pode estar relacionada com a pouca freqüência de observações próximas aos quantis estimados, o que gera aumento da variância e, conseqüentemente, do desvio padrão.

20 A questão da convergência ainda é um assunto controverso na literatura, principalmente com a introdução dos modelos de crescimento econômico que assumem rendimentos crescentes de escala. Haveria convergência condicional se os países relativamente mais distantes de seus produtos de steady state crescessem a taxas mais rápidas, ou seja, haveria a formação de clubes de convergência. Contudo, esta hipótese não pode ser confirmada com os resultados obtidos neste trabalho. Uma possível explicação para este fato pode estar relacionada à heterogeneidade dos países analisados neste trabalho, pois tanto países desenvolvidos quanto em desenvolvimento são considerandos. Para uma análise sobre convergência, ver Barro e Sala-i-Martin (1992) e Barro (1991). Para um estudo sobre convergência usando o método de regressão quantílica, ver Barreto e Hughes (2004). 
O modelo que tem a variável BANCO como variável explicativa e controlada por características cross-country é visto na Tabela 4. Quando se analisa o efeito da variável BANCO na distribuição condicional da variável taxa de crescimento real do PIB per capita, percebe-se que somente dois quantis são estatisticamente significativos: quantil 0,50 e quantil 0,75. Nestes dois quantis os coeficientes ficaram praticamente iguais, com magnitude ao redor de 5,65\%. As evidências são mais contundentes quando se investiga o modelo que tem a variável taxa de crescimento do capital como variável explicada. Neste modelo há a nítida tendência de crescimento na magnitude do coeficiente quando se desloca do quantil menor $(3,80 \%)$ para o maior $(8,98 \%)$, evidenciando, novamente, a idéia de que o sistema financeiro tem uma função mais ativa nos países de crescimento mais acelerado.

Taxa de inflação e crescimento da educação têm os sinais convencionais sugeridos pela literatura, negativo e positivo, respectivamente. Quando se analisam os coeficientes angulares da renda per capita inicial não se pode inferir sobre a existência ou não de convergência, pois há evidências para os dois casos, dependendo do quantil analisado. A variável comércio internacional foi a única a apresentar sinal contrário ao indicado pela teoria econômica. Contudo, os coeficientes estatisticamente significativos estão muito próximos de zero, ou seja, a sua contribuição para o crescimento econômico é praticamente nula: ao redor de $-0,02 \%$.

Nos modelos acima (Tabelas 3 e 4) foram realizados testes para averiguar se as estimativas dos coeficientes em cada quantil são estatisticamente diferentes entre si. ${ }^{21}$ A técnica utilizada, bootstrap, foi aplicada em duas etapas: i) com 20 repetições; e ii) com 100 repetições. Em ambos os casos, os resultados qualitativos não se alteraram. Para o modelo da Tabela 3, não foi possível rejeitar a hipótese nula de igualdade de coeficientes. Contudo, no modelo da Tabela 4, esta hipótese é rejeitada, pois há pelo menos dois coeficientes (de quantis distintos) que são estatisticamente diferentes. Em outros termos, pode-se afirmar que o impacto causado pelo sistema financeiro é assimétrico ao longo da distribuição condicional da variável resposta. Neste sentido, técnicas convencionais, que são voltadas somente para a média condicional, são incapazes de capturar esse efeito. Por isto, o emprego de regressão quantílica torna-se mais atrativo, pois com esta metodologia mais informação pode ser obtida dos dados.

\section{CONCLUSÃO}

Explicar as diferentes taxas de crescimento entre os países vem sendo uma agenda importante na economia. Modelos mais recentes (modelos de crescimento endógeno, por exemplo) chegam à conclusão que uma possível explicação para as diferenças de crescimento, entre outras, está relacionada com a taxa de poupança, pois o volume de recursos alocados para o investimento depende da taxa de poupança interna e, para o caso de uma economia aberta, também da taxa de poupança externa. Em ambas as situações a intermediação financeira parece ser um sinalizador de eficiência, pois esta possui a característica de afetar a alocação dos recursos financeiros.

Nesse sentido, o propósito deste trabalho foi examinar os canais pelos quais o desenvolvimento financeiro está relacionado com o crescimento econômico. A argumentação girou em torno dos serviços que o sistema financeiro oferta (suas funções), e que se traduzem na promoção da eficiência alocativa dos recursos financeiros. A literatura afirma que quanto maior a atuação do sistema financeiro, maior será o volume de recursos alocados no setor produtivo e, conseqüentemente, maior o crescimento econômico.

21 Esse teste foi aplicado para as variáveis de interesse, referentes ao sistema financeiro (intensidade financeira e banco). 
A evidência empírica encontrada neste trabalho corrobora a visão teórica de que há indicativos de uma relação positiva entre desenvolvimento financeiro e crescimento econômico. A técnica de regressão quantílica foi aplicada, e produziu um mapeamento mais completo do impacto gerado pelas medidas de desenvolvimento financeiro na distribuição condicional da variável resposta (medidas de crescimento econômico).

As estimativas produzidas por regressão quantílica permitem concluir que: a) há uma relação positiva entre desenvolvimento financeiro e crescimento econômico; b) mesmo controlando por características cross-country, os parâmetros estimados se mantêm positivos; e c) quanto maior o quantil (isto é, maior a taxa de crescimento econômico), maior é a contribuição do sistema financeiro para o crescimento econômico.

Também foram realizados testes de hipótese para verificar se os coeficientes estimados para cada quantil são diferentes estatisticamente. Os resultados desses testes apontam para evidências favoráveis, ou seja, as variáveis utilizadas com proxy para o sistema financeiro afetam de forma assimétrica a distribuição condicional da variável resposta. Cabe salientar ainda que este resultado pode ser obtido pelo uso de regressão quantílica. Métodos convencionais não capturam esta informação, pois a análise se detém somente à média condicional, ou seja, toda a distribuição condicional da variável resposta é representada somente pela média. Em situações em que a distribuição da variável dependente é afetada assimetricamente pelas covariáveis, como é o caso do modelo utilizado neste trabalho, tal método perde atratividade.

Faz-se necessária uma investigação mais apurada da terceira evidência encontrada neste trabalho. Como dito acima, países com maior crescimento econômico são mais afetados (positivamente) pelo desenvolvimento financeiro. Tal evidência pode ser explicada pelo fato de os países que possuem maiores taxas de crescimento serem, em geral, os que possuem um estoque de capital menor se comparados com países desenvolvidos. ${ }^{22}$ Neste sentido, qualquer instrumento que afete a eficiência da alocação do capital (desenvolvimento financeiro, neste caso) causa um maior retorno marginal do capital ${ }^{23}$ para estes países. Por este motivo, então, os coeficientes angulares das variáveis de desenvolvimento financeiro são maiores nos quantis mais altos do que os quantis inferiores.

O sistema financeiro tem uma significativa correlação como as variáveis de crescimento econômico, sendo este, então, um bom sinalizador para o um bom desempenho de uma economia. Neste sentido, a intuição de Schumpeter acerca do sistema financeiro parece ser apropriada, pois há evidências de uma relação estreita entre inovação e desenvolvimento financeiro.

Com base nos resultados obtidos neste artigo, recomenda-se que os próximos trabalhos que visem analisar a relação entre sistema financeiro e crescimento econômico tenham a preocupação de investigar como a distribuição da variável resposta é impactada pelas covariáveis, para que, desta forma, o melhor método seja escolhido. No caso do presente artigo, o mais apropriado foi o uso de regressão quantílica, visto que esta proporcionou um melhor detalhamento da relação entre as variáveis, reportando informação que não poderia ser obtida por métodos baseados na média condicional.

Um fator importante que não foi abordado neste trabalho diz respeito ao ambiente institucional $^{24}$ de cada país. Este pode afetar as variáveis de desenvolvimento financeiro e, por conseqüência, impactar as taxas de crescimento dos países. Levine (1999) criou alguns indicadores para o ambiente legal dos países, encontrando uma relação positiva entre estes e as variáveis de desenvolvimento financeiro. Contudo, ainda há um campo grande de pesquisa nessa direção.

22 Países desenvolvidos teriam uma taxa de crescimento menor por estarem mais próximos do estado estacionário.

23 Supondo uma função de produção côncava, como é o habitual em economia.

24 Uma excelente resenha sobre este assunto encontra-se em North (1990). 


\section{REFERÊNCIAS BIBLIOGRÁFICAS}

Arkelof, George. The market for 'lemons': quality, uncertainty and market mechanism. Quarterly Journal of Economic 84, p. 488-500, 1970.

Barreto, Raul A.; Hughes, Anthony W. Under performers and over achievers: a quantile regression analysis of growth. The Economic Record, v. 80, n. 248, p. 17-35, 2004.

Barro, Robert. Economic growth in a cross-section of countries. Quarterly Journal of Economics, 106, p. 407-43, 1991.

Barro, Robert; Sala-i-Martin, Xavier. Convergence. Journal of Political Economy, v. 100, n. 2, p. 223-251, 1992.

. Economic growth. McGraw Hill, 1995.

Bebczuk, Ricardo. Asymmetric information in financial markets: introduction and applications. Cambridge University Press, 2003.

. Corporate finance, financial development and growth. Mexico, D. F.: Centro de Estudos Monetarios Latinoamericanos (Central Bank Award “Rodrigo Gómez 2000”), 2001.

Becsi, Zsolt; Wang, Ping. Financial development and growth. Economic Review, Federal Reserve Bank of Atlanta. $4^{\text {th }}$ quarter, 1997.

Bencivenga, Valeria R.; Smith, Bruce. Financial intermediation and economic growth. The Review of Economic Studies, v. 58, n. 2, p. 194, abril 1991.

Carvalho, Antônio Gledson. Desenvolvimento financeiro e crescimento econômico. Revista Econômica do Nordeste, Fortaleza, v. 33, n. 4, p. 694-715, 2002.

Goldsmith, Raymond. Financial structure and development. New Haven and London: Yale University Press, 1969.

Khan, Aubhik. Financial development and economic growth. Federal Reserve Bank of Philadelphia, Working Paper n. 99-11, setembro 1999.

Koenker, R.; Bassett, G. Regression quantile. Econometrica, 46, p. 33-50, 1978.

Levine, R. Financial development and economic growth: views and agenda. Journal of Economic Literature, 35, 1997.

. Law, finance and economic growth. Journal of Financial Intermediation 8, p. 8-35, 1999.

Levine, R.; Loyaza, N. Beck, T. Financial intermediation and growth: causality and causes. Journal of Monetary Economics, v. 46, n. 1, p. 31-77, 2002.

Lucas Jr., Robert. On the mechanics of economic development. Journal of Monetary Economics. 22, p. 342, julho, 1988.

Mankiw, N. Gregory; Romer, David; Weil, David. A contribution to the empirics of economic growth. Quarterly Journal of Economics 107, p. 407-38, maio 1992.

Mishkin, Frederic. Moedas, bancos e mercados financeiros. $5^{\text {a }}$. ed. Rio de Janeiro: LTC, 2000.

North, Douglass C. Institutions, institutional change and economic performance. Cambridge University Press, 1990.

Pagano, Marco. Financial markets and growth. European Economic Review 37, p. 613-22, abril 1993.

Rebelo, Sérgio. Long-run policy analysis and long-run growth. Journal of Political Economy, v. 99, n. 3, p. 500-521, 1991.

Romer, David. Advanced macroeconomics. $2^{\text {nd }}$ ed. McGraw Hill, 2001.

Romer, Paul M. Increasing returns and long-run growth. Journal of Political Economics 94, p. 1000-37, outubro 1986. 
Schumpeter, Joseph. The theory of economic development. Cambridge. Mass.: Harvard University Press, 1911.

Shaw, E. W. Financial deepening in economic development. New York: Oxford University Press, 1973.

Solow, Robert. A contribution to the theory of economic growth. Quarterly Journal of Economics, 70, p. 65-94, fevereiro 1956.

Wooldridge, Jeffrey M. Introductory econometrics: a modern approach. USA: South-Western College Publishing, 2000. 